Palavras chave: Anatomia quali-quantitativa Anatomia ecológica Douradinha-do-campo Plasticidade morfológica

Histórico: Recebido 20/09/2015 Aceito 26/04/2016

Keywords: Leaf sclerophylly Qualitative anatomy Ecological Anatomy Douradinha-do-campo Morphological plasticity

Correspondência: mlgavilanes@dbi.ufla.br
Manuel Losada Gavilanes', Evaristo Mauro de Castro', Marinês Ferreira Pires', Fabricio José Pereira', Márcio Paulo Pereira'

\section{MICROMORFOMETRIA FOLIAR DE PALICOUREA RIGIDA KUNTH. (RUBIACEAE) EM AMBIENTE DE CERRADO E CAMPO RUPESTRE}

RESUMO: Este trabalho teve como objetivo um estudo anatômico descritivo e quantitativo da estrutura foliar de Palicourea rigida Kunth. (Rubiaceae), espécie que ocorre em áreas de cerrado e campo rupestre. As observações anatômicas foram realizadas em folhas de material fresco ou fixado, tratadas segundo metodologias usuais em anatomia vegetal. Foram observadas as seguintes características: epidermes do pecíolo e da lâmina foliar uniestratificadas; presença de tricomas tectores, simples, unisseriados, próximos, ou sobre as nervuras; estômatos do tipo paracítico presentes somente na face abaxial da folha; mesofilo com parênquima paliçádico de uma só camada de células; parênquima esponjoso com sete a nove camadas celulares com formas irregulares e tamanhos variados; idioblastos cristalíferos, observados em todos os parênquimas do pecíolo e lâmina foliar; feixes vasculares, do tipo colateral; colênquima observado, subepidermicamente, no pecíolo e nervuras de maior porte, em ambas faces; o padrão geral de nervação da espécie é pinado, camptódromo, broquidódromo. As análises micromorfométricas revelaram diferenças significativas em todos os itens analisados, sendo as médias mais elevadas encontradas nas folhas das plantas crescendo no cerrado. Isto sugere que a influência de fatores ambientais pode ter modulado respostas morfológicas nas plantas, visto que o tipo e distribuição dos tecidos não sofreram alterações nos dois ambientes.

\section{LEAF MICROMOPHOMETRY OF PALICOUREA RIGIDA KUNTH. (RUBIACEAE) FROM BRAZILIAN CERRADO AND CAMPO RUPESTRE ENVIRONMENTS}

ABSTRACT: The objective of this work was to evaluate qualitative and quantitative leaf anatomical traits of Palicourea rigida Kunth. (Rubiaceae) species occurring in the Brazilian Cerrado and Campo Rupestre ecosystems. Anatomical analysis was performed in fresh or fixed leaves processed with usual plant microtechnique. Leaves showed uniseriate epidermis in petiole and leaf blade which contains uniseriate nonglandular tricomes (tector type) occurring only over the vascular bundles. Likewise, paracytic stomata were found only in abaxial side of the leaf surface. The mesophyll contains uniseriate palisade parenchyma and multiseriate spongy parenchyma (nine layers) which showed cells with different morphology and size. Crystal idoblasts of different types were observed in both the petiole and leaf blade. Collateral vascular bundles were found both in the petiole and leaf blade. Leaf venation type was pinnate, campylodromous or brochydodromous. The micromorphometric analysis showed significant differences from plants of different environments for all leaf characteristics and Cerrado plants showed higher means for all evaluated traits. Therefore, the influence of environments may had modulated morphological responses in $P$. rigida, since no difference was found in the type or distribution of leaf tissues in Cerrado or Campo Rupestre. 


\section{INTRODUÇÃO}

A família Rubiaceae possui, segundo Robbrecht (1988), cerca de 640 gêneros e 12.000 a 13.000 espécies, essencialmente tropicais. Esta família ocupa o quarto lugar em diversidade entre as Angiospermas (MABBERLEY, 1997). As Rubiáceas podem ser classificadas, segundo Barroso et al. (1986), como árvores de grande, médio a pequeno porte, arbustos, subarbustos, ervas perenes ou anuais; plantas escandentes, lianas, cipós, ervas prostadas, decumbentes e mais raramente epífitas. É uma família característica da flora brasileira, ocorrendo em praticamente todas as formações vegetais. Os caracteres diagnósticos mais úteis no reconhecimento da família são encontrados nas folhas opostas com estípulas interpeciolares (ROBBRECHT, 1988).

Rubiaceae possui espécies de grande importância econômica, que são exploradas como alimentícias (Coffea arabica L., Genipa americana L.), ornamentais (Ixora spp.), e também na indústria farmacêutica, como por exemplo Cinchona pubescens Vahl, produtora de quinina, empregada no tratamento da malária. Várias espécies são referidas popularmente como medicinais (Coutarea hexandra (Jacq.) K. Schum) e/ou tóxicas (espécies de Palicourea Aubl. e Psychotria L., popularmente conhecidas como "mata-ratos") (MENDONÇA et al., 20I 3). Segundo Freitas et al. (20I I) extratos aquosos e hidroalcoólicos de Palicourea rigida tem sido tradicionalmente empregados no tratamento de patologias do sistema urinário, o que provavelmente se deva a produção da loganina, afirmação que é compartilhada por Silva et al. (20l3), que denotam preocupação com o fato de a espécie correr sério risco de extinção. Oliveira et al. (20l4) demonstraram que a taxa de germinação de sementes e desenvolvimento da plântula de alface, foram afetadas por extratos de folhas de Palicourea rigida, evidenciando afeito alelopático.

No Brasil, o gênero Palicourea Aubl., possui a maioria das espécies com distribuição geográfica restrita, evidenciando marcado endemismo, em particular em campos rupestres dos estados de Minas Gerais, Bahia e Goiás. Atualmente, considera-se que o gênero é constituído por 2I espécies, das quais II ocorrem em Minas Gerais, sendo a sua maior concentração na Serra do Espinhaço (BARROSO et al., 1986).

Trabalhos em anatomia têm servido de base a vários outros campos da Botânica como a fisiologia, a taxonomia e a botânica aplicada, entre outras áreas. 0 conhecimento da estrutura interna da planta indica e explica sua adaptação a determinado ambiente. Essa tem sido uma preocupação dos botânicos que trabalham com anatomia ecológica (METCALFE, 1979).
São poucos os estudos anatômicos realizados com espécies do gênero Palicourea Aubl., realizados no Brasil, podendo ser citado o trabalho de Pereira et al. (2003), que estudaram a estrutura anatômica folha de Palicourea longipedunculata Gardiner, espécie ocorrente em ambiente de mata.

Este trabalho teve como objetivo um estudo anatômico descritivo e quantitativo da estrutura foliar de Palicourea rigida, espécie que ocorre em áreas de cerrado e de campo rupestre.

\section{MATERIAL E MÉTODOS}

O material, botânico, estudado é proveniente de coletas realizadas em áreas remanescentes de cerrado e de campo rupestre, localizadas na Serra do Campestre, dentro do Município de Lavras, MG., nas coordenadas $2 I^{\circ} 20^{\prime} 00.42^{\prime \prime} S$ e 44 58'09.66" O, a uma altitude de $104 \mathrm{I}$ m e $21^{\circ} 20^{\prime} 19.45^{\prime \prime}$ S e 445' $38.40^{\circ}$ ' O, a uma altitude de I 59 m, respectivamente. Para a identificação da espécie, baseou-se nos trabalhos de Campos et al. (2006) e Zappi et al. (2014) e na observação e de exemplares depositados no herbário ESAL (Herbário do Departamento de Biologia da Universidade Federal de Lavras - UFLA, Lavras, MG). Amostras do material botânico encontram-se depositados no Herbário ESAL, sob os números ESAL 28485 (espécime coletado em cerrado) e ESAL 28486 (espécime coletado em campo rupestre).

O estudo anatômico foi realizado em material fresco e fixado. A fixação foi realizada no local de coleta, sendo empregados os fixadores: FAA, com graduação alcoólica de $70^{\circ} \mathrm{GL}$, por um período de 72 horas, posteriormente transferido e conservado em etanol $70^{\circ} \mathrm{GL}$ até a data das análises (JENSEN, 1962). Foram utilizadas folhas completamente desenvolvidas, coletadas no $5^{\circ}$ nó.

Os cortes histológicos foram realizados à mão livre com auxílio de lâmina de aço. Os cortes foram praticados em diferentes posições ao longo da nervura mediana e da lâmina foliar. No estudo da epiderme, em vista frontal, utilizaram-se cortes paradérmicos ou o seu isolamento pelo método de Jeffrey (KRAUS; ARDUIN, 1997). Foram confeccionadas lâminas semipermanentes, utilizando-se como meio de montagem o glicerol a 50\% em água. A coloração das secções transversais da lâmina foliar e do pecíolo, foi feita com solução de azul de astra e safranina, ambos a $1 \%$ em água, na proporção de 9:। (KRAUS; ARDUIN, 1997).

A contagem dos estômatos e todas as medidas concernentes foram realizados em três regiões: base, meio e ápice da lâmina foliar. Para as observações 
transversais e longitudinais das células estomáticas, as folhas, das espécies estudadas, foram seccionadas transversalmente à nervura mediana na região do terço médio (BEIGUELMAN, 1962). A classificação básica dos estômatos foi baseada em Metcalfe e Chalk (1950).

Nos testes histoquímicos, cortes foram submetidos a reagentes específicos; a identificação da lignina foi feita com o uso de floroglucina adicionada com gotas de ácido clorídrico concentrado ou solução aquosa de ácido sulfúrico a 50\% (FOSTER, 1949); cutícula e camadas cutinizadas foram evidenciadas com o emprego de Sudan IV em solução hidroalcoólica a $80 \%$ (FOSTER 1949); a celulose foi identificada pelo reativo de iodoiodeto de potássio em ácido sulfúrico, e a natureza química de cristais foi identificada utilizando-se solução aquosa de ácido sulfúrico a 5 e 10\% (KRAUS; ARDUIN, 1997).

No estudo da nervação, utilizaram-se folhas de material herborizado e material fixado. As folhas, ou fragmentos, foram diafanizadas em solução aquosa de hidróxido de sódio a $5 \%$, solução renovada diariamente até a completa clarificação das folhas; em seguida foram clarificadas em hipoclorito de sódio $50 \%$, e coradas com solução hidroalcoólica de safranina a I\% (FELLIPE; ALENCASTRO, 1966). A descrição dos caracteres gerais das folhas e tipos de nervuras foram baseados em Hickey (1973).

Os desenhos e esquemas dos pormenores anatômicos foram realizados com o auxílio de câmara clara (tubo de desenho) acoplada em microscópio óptico Olympus $\mathrm{CBB}$, tendo sido projetada uma escala micrométrica nas mesmas condições em que foram feitos os desenhos e esquemas. Os diagramas seguiram a orientação de Metcalfe e Chalk (1950).

Para o estudo quantitativo foram analisadas duas lâminas por folha (20 folhas) e duas secções por lâmina, sendo observadas ao microscópio de luz acoplado à câmera digital e realizada uma fotomicrografia de cada secção, totalizando 80 campos por tratamento e quatro campos por folha. Foi realizada a média de todos os campos mensurados, para cada folha amostrada. Os parâmetros anatômicos quantitativos foram analisados com o auxílio do software de análise de imagem Image (National Institutes of Health, Bethesda, Maryland, USA) calibrado com régua microscópica fotografada nos mesmos aumentos das fotomicrografias. Para as análises biométricas, as folhas foram escaneadas em scanner de mesa. As imagens escaneadas foram utilizadas para cálculo do comprimento e largura da lâmina, além da área foliar.

Foi realizada a análise de variância com o teste de $F$ para detectar as diferenças entre os tratamentos e o teste de Scott-Knott para $\mathrm{p}<0,05$ para o estudo das médias em software de análise estatística (Sisvar 5.0) (FERREIRA, 20II). O delineamento experimental foi inteiramente casualizado com dois tratamentos (ambiente de cerrado e de campo rupestre) e 20 repetições. A parcela experimental foi constituída de uma folha.

\section{RESULTADOS E DISCUSSÃO}

\section{Descrição morfológica}

A espécie estudada (Figura I) foi encontrada no ambiente de cerrado e campo rupestre, com hábito arbustivo ou subarbustivo, com ramos cilíndricos, raramente tetragonais, esparsamente pubérulos e ramos basais fortemente suberificados. Folhas opostas a falsamente verticiladas, curtamente pecioladas a subsésseis, lâmina elíptica a oboval, base aguda, margens espessadas, ápice arredondado a retuso, raramente agudo, coriáceas, esparsamente pubérula a glabrescente, nervuras secundárias 9-18 pares, salientes em ambas as faces, amareladas em folhas vivas; estípulas bipartidas, persistentes. É de fácil reconhecimento através dos ramos suberificados e das inflorescências com flores amareloalaranjadas. Durante os trabalhos de campo observou-se que a espécie floresce de agosto a dezembro e frutifica no mês de dezembro.

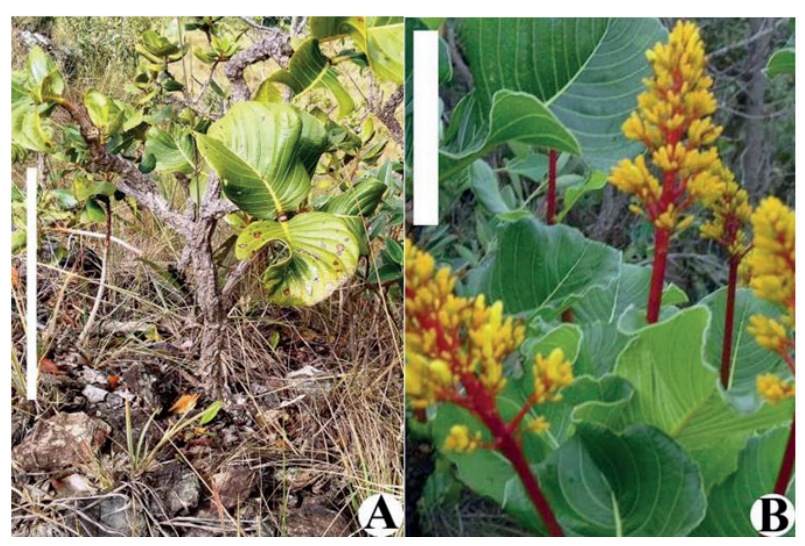

FIGURA I A - Hábito de Palicourea rigida, em campo rupestre; B - Inflorescência. Barras = 30,0 cm (A); 10,0 cm (B).

FIGURE I A - Palicourea rigida growing in campo rupestre environment. $B$ - inflorescence. Bars $=30 \mathrm{~cm}(A)$ and $10 \mathrm{~cm}(B)$.

\section{Anatomia descritiva da folha}

\section{Pecíolo}

A região mediana do pecíolo, em secção transversal, apresenta a superfície adaxial ligeiramente convexa e a abaxial, convexa, com um formato geral 
próximo ao circular (Figura 2-A). A epiderme é uniestratificada, com células de paredes espessadas, sem estômatos, e apresenta tricomas tectores unicelulares, semelhantes àqueles observados próximo as nervuras de grande porte (Figura 3-E). A região cortical do pecíolo é nitidamente dividida em duas porções: uma periférica, constituída por oito à dez camadas de colênquima, do tipo angular, e uma mais interna, constituída por células parenquimáticas. Idioblastos contendo cristais de oxalato de cálcio em forma de ráfides (Figura 4-E), estilóides e prismáticos, estes variando de formas de monocristais até drusas, são comuns na região cortical. $\mathrm{Na}$ região central do pecíolo situa-se o sistema vascular, composto por feixes vasculares do tipo colateral, arranjados em forma de "U", com as extremidadesfortementefletidas. Estacaracterísticanãofoi observada no pecíolo de Palicourea longepedunculata, por Pereira et al. (2003), mas foi constatada em Tocoyena bullata (Vell.) Mart., por Vieira ( 1988). O sistema vascular é acompanhado, em toda a extensão, por dois feixes laterais menores, conforme mencionado por Metcalfe e Chalk (1950), como sendo comum em rubiáceas, padrão este referenciado por Gomes et al. (1995) e Vieira et al. (1992) para espécies de Psychotria L. Externamente ao floema, são visíveis grupos de fibras esclerenquimáticas.

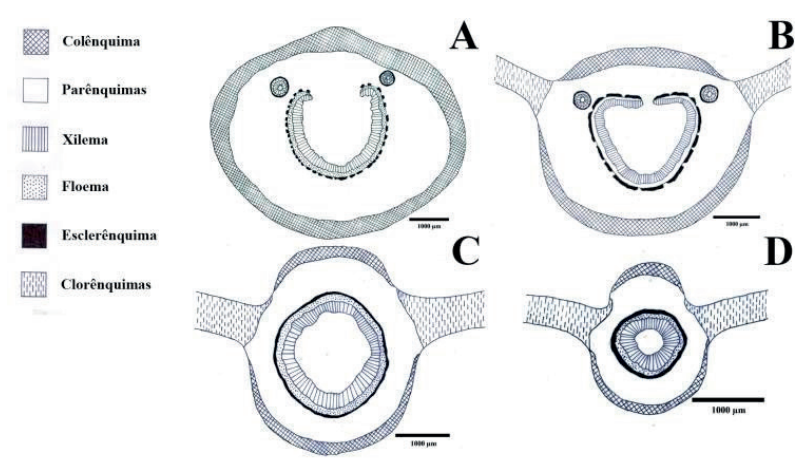

FIGURA 2 Esquemas de cortes transversais: A - Pecíolo; B Nervura mediana, na porção basal; C - Nervura mediana, na porção mediana; D - Nervura mediana, na porção apical. Barras $=1000 \mu \mathrm{m}$.

FIGURE 2 Scheme of Palicourea rigida leaves in transversal sections. A - Petiole; B- Midrib at leaf base; C-Midrib at leaf median portion; $\mathrm{D}-$ Midrib at leaf apex. Bars = $1000 \mu \mathrm{m}$.

\section{Lâmina Foliar}

\section{Epiderme da face adaxial}

Apresenta, em vista frontal (Figura 3A), células de contorno poligonal e irregulares quanto ao tamanho e distribuição; as paredes anticlinais apresentam-se retas a ligeiramente curvas. Sobre as nervuras de maior porte, e ao longo destas, adquirem formato alongado (Figura 3-C). Vista em corte transversal (Figura 4-A), é uniestratificada. As paredes periclinais externas são ligeiramente convexas, e cobertas por cutícula de espessura irregular. As paredes periclinais internas são menos espessadas que as externas.

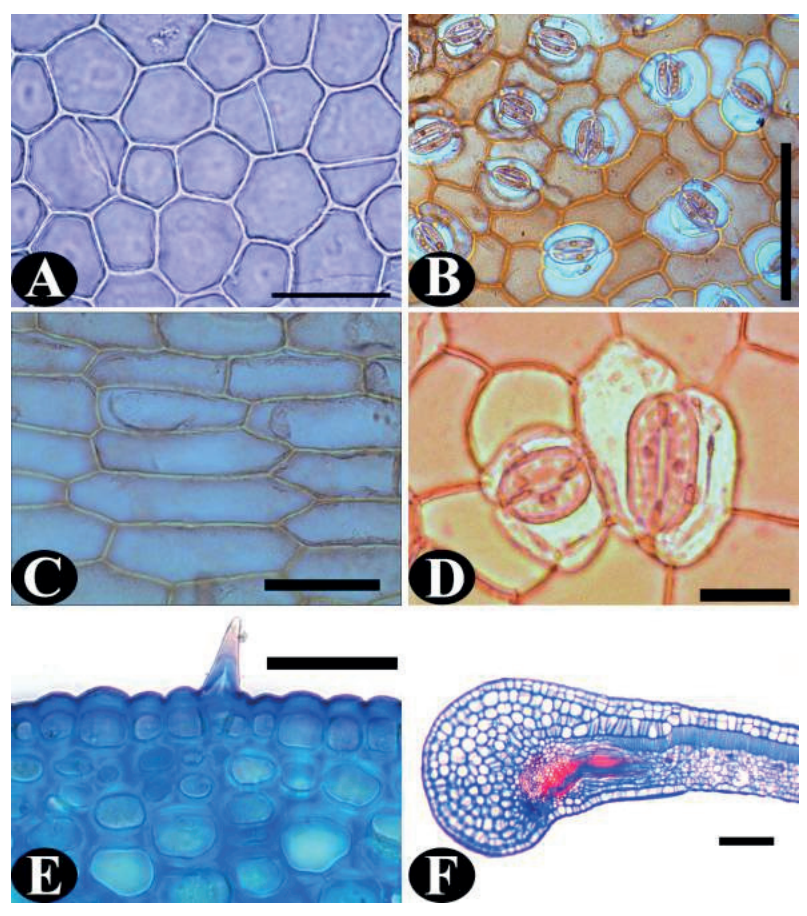

FIGURA 3 P. rigida. A - D: epiderme foliar; A: epiderme da face adaxial; B: epiderme da face abaxial; C: epiderme da face adaxial sobre nervura secundárias; $D$ : estômato geminado. E: Epiderme, tricoma e colênquima da nervura mediana na região mediana. F: bordo foliar. Barras $=50 \mu \mathrm{m}(\mathrm{A}-\mathrm{E}) ; 200 \mu \mathrm{m}(\mathrm{F})$.

FIGURE 3 P. rigida. A - D: leaf epidermis; A: adaxial side epidermis; A: abaxial side epidermis; $C$ : adaxial side epidermis over secondary veins; D: geminate stomata; E: epidermis, trichome and collenchyma from the midirib at the leaf center. F: leaf margin. Bar $=50 \mu \mathrm{m}(\mathrm{A}-\mathrm{E})$; $200 \mu \mathrm{m}(\mathrm{F})$.

\section{Epiderme da face abaxial}

Também apresenta células de contorno poligonal, irregulares quanto ao tamanho, sem arranjo definido, e com paredes anticlinais retas a ligeiramente curvas. Apresenta estômatos (Figura 3-B). Vista em corte transversal, é uniestratificada (Figura 4-A). Paredes periclinais externas recobertas por cutícula fina, lisa e de espessura quase uniforme. As paredes periclinais internas são mais finas que as paredes periclinais externas. 


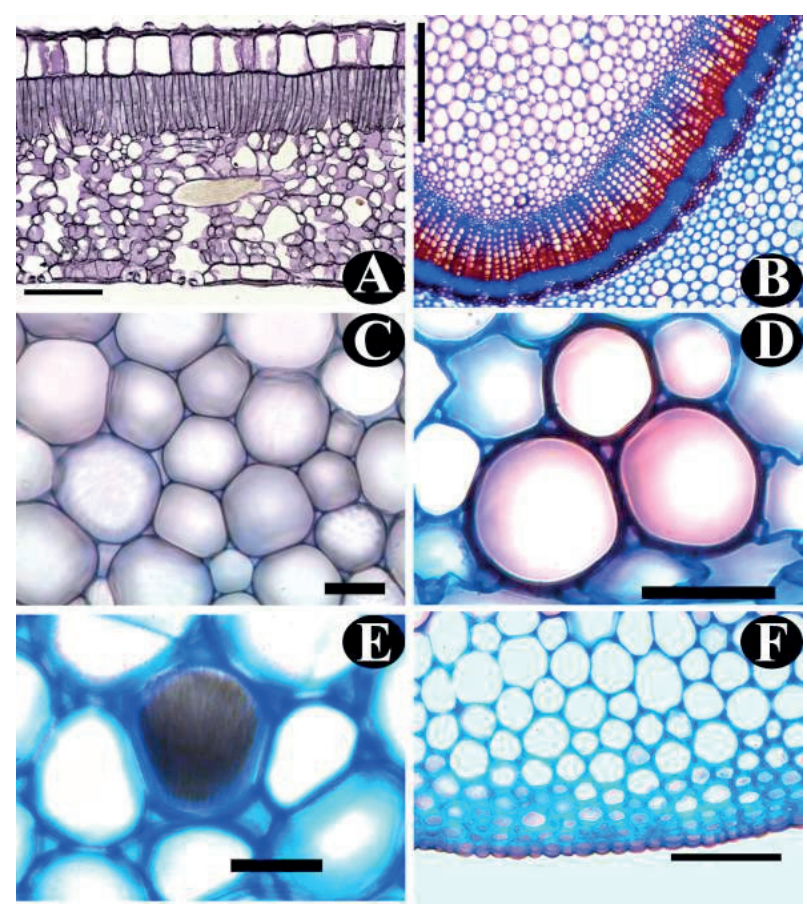

FIGURA 4 P. rigida. A: lâmina foliar em secção transversal. B - E: tecidos da nervura mediana em cortes transversais; $B$ : parênquima e tecidos do sistema vascular; C - E: parênquima fundamental; em E, feixe de rafídios; F: epiderme e colênquima. Barras $=100 \mu \mathrm{m}(\mathrm{A}-\mathrm{B}) ; 50 \mu \mathrm{m}(\mathrm{C}-\mathrm{F})$.

FIGURE 4 P. rigida. A: transversal section of leaf blade; $B-E$ : transversal sections of the midrib tissues; B: parenchyma and vascular tissues; C-E: ground parenchyma; $\mathrm{E}$ : raphids bundle; $\mathrm{F}$ : epidermis and collenchyma. Bars $=100 \mu \mathrm{m}(\mathrm{A}-\mathrm{B}) ; 50 \mu \mathrm{m}(\mathrm{C}-\mathrm{F})$.

\section{Estômatos}

Presentes somente na face abaxial (Figura 3 B) da folha, caracterizando-a como hipoestomática. São do tipo paracítico (rubiáceo), segundo a classificação de Metcalfe e Chalk (1950). Em vista frontal, acham-se dispersos sem qualquer arranjo perceptível. Nota-se, comumente, a ocorrência de estômatos vizinhos duplos ou muito próximos (Figura $3 \mathrm{D}$ ). Em corte transversal, as células estomáticas estão situadas no mesmo nível das demais células epidérmicas (Figura 4 - A). A câmara subestomática é pouco profunda, e se estende, até as proximidades da penúltima camada do parênquima esponjoso.

\section{Tricomas}

Ocorrem esparsamente nas duas faces da folha, sendo mais numerosos nas proximidades e sobre as nervuras de maior porte (Figura 3 E). São unicelulares e com paredes celulares de espessura aproximadamente uniforme. Por suas características podem ser classificados como tricomas tectores. Esse tipo de tricoma foi observado por Pereira et al. (2003) em Palicourea longipedunculata, espécie encontrada no interior de mata, e por Vieira et al. (1992) em Psychotria leiocarpa Mart., também citada como ocorrente em mata.

\section{Mesofilo}

A secção da lâmina foliar, em sua região mediana, apresenta estrutura dorsiventral (Figura 4 A). $O$ parênquima paliçádico é constituído por um único estrato celular (Figura 4 A). As células encontram-se dispostas de maneira compacta com muito poucos espaços intercelulares. O parênquima esponjoso é constituído por sete - nove camadas de células, que apresentam formatos e tamanhos irregulares e paredes finas (Figura 4 A). O conteúdo celular é mais escasso que o das células paliçádicas. Os espaços intercelulares (lacunas) são relativamente pequenos. Em todo o mesofilo ocorrem idioblastos, portadores de estruturas cristalinas de oxalato de cálcio, com formatos semelhantes aos já citados para o pecíolo, distribuídas aleatoriamente. Os estiloides na maioria das observações ocorrem no parênquima paliçádico.

\section{Nervuras}

Em secção transversal, a nervura primária (mediana) apresenta-se convexa tanto na região abaxial como na adaxial, desde a base até o ápice, sendo mais evidente a partir da região mediana (Figuras 2 B, C, D). A epiderme, tanto na face adaxial como na abaxial, em corte transversal (Figura 3 - E, 4 - F) é uniestratificada com paredes periclinais espessadas, sendo a externa recoberta por cutícula semelhante à observada sobre as células do pecíolo. Há presença de tricomas tectores. Subepidermicamente há um colênquima, do tipo angular, com número variável de camadas celulares, de acordo com a região em que é realizado o corte (Figura 3- E, 4 F). De modo geral, as células que se encontram próximas à epiderme possuem menor diâmetro que o das camadas celulares mais internas. O sistema vascular (Figuras $2 \mathrm{~B}$, C, D) é semelhante ao descrito para o pecíolo, havendo alteração na disposição dos feixes vasculares; a partir da região mediana, até a região apical, posicionam-se formando uma estrutura circular, rodeada, externamente ao floema, por uma bainha de fibras esclerênquimáticas (Figuras 2 C, D). O parênquima fundamental é constituído por células com paredes delgadas. Notamse, neste tecido, idioblastos cristalíferos, semelhantes aos já descritos para o pecíolo. As nervuras secundárias apresentam-se idênticas à primária no terço médio da folha, notando-se, porém uma redução das camadas 
celulares que as compõem. As nervuras de menor calibre apresentam constituição muito variável, conforme o seu calibre, podendo as mais reduzidas constarem exclusivamente de elementos do xilema.

\section{Bordo Foliar}

Apresenta-se ligeiramente fletido em direção à face abaxial (Figura 3F). As células epidérmicas, dispostas em uma só camada celular, apresentam-se diferentes, em forma e tamanho, das células das faces adaxial e abaxial. Toda a região, propriamente dita do bordo, é recoberta por cutícula semelhante àquela que recobre o restante da lâmina foliar, porém apresenta uma maior espessura. À medida que se aproximam do bordo, as células do parênquima paliçádico tornam-se mais curtas e mais estreitas; no parênquima esponjoso também ocorre uma diminuição do número de camadas celulares. Na porção mais dilatada do bordo essas células são substituídas por um grupo de elementos colenquimatosos. Cristais, dos tipos já descritos, ocorrem com relativa frequência nessa região. Tricomas com as mesmas características já assinaladas ocorrem, raramente nesta região; estômatos não foram observados.

\section{Nervação}

Padrão geral (Figura 5A): pinado, camptódromo, broquidódromo. A nervura mediana (nervura primária) é nítida, afilando-se em direção ao ápice, com curso retilíneo, sem ramificações. As nervuras secundárias são ascendentes, apresentando ângulo de divergência agudo; espessura moderada; curso levemente no percurso até próximo ao bordo foliar, e curvado abruptamente formando arcos com as nervuras secundárias supra-adjacentes. As nervuras terciárias são visíveis na folha verde. As nervuras de maior ordem apresentam curso relativamente ao acaso (Figura 5 B). As nervúrulas (Figura 5 C, D) são simples e ramificadas; são encontradas aréolas sem nervúrulas. As aréolas (Figura 5 C, D) apresentam desenvolvimento imperfeito, com arranjo ao acaso, formato irregular e tamanho predominantemente mediano.

A densidade vascular das folhas oriundas do campo rupestre é maior, o que pode ser observado na figura $5 \mathrm{D}$, que representa aréolas e terminações de nervuras. A figura $5 \mathrm{C}$ representa areólas e terminações de nervuras de folhas provenientes do cerrado.

\section{Anatomia quantitativa da folha}

A morfologia externa das folhas de $P$. rigida foi claramente modificada pelos diferentes ambientes.
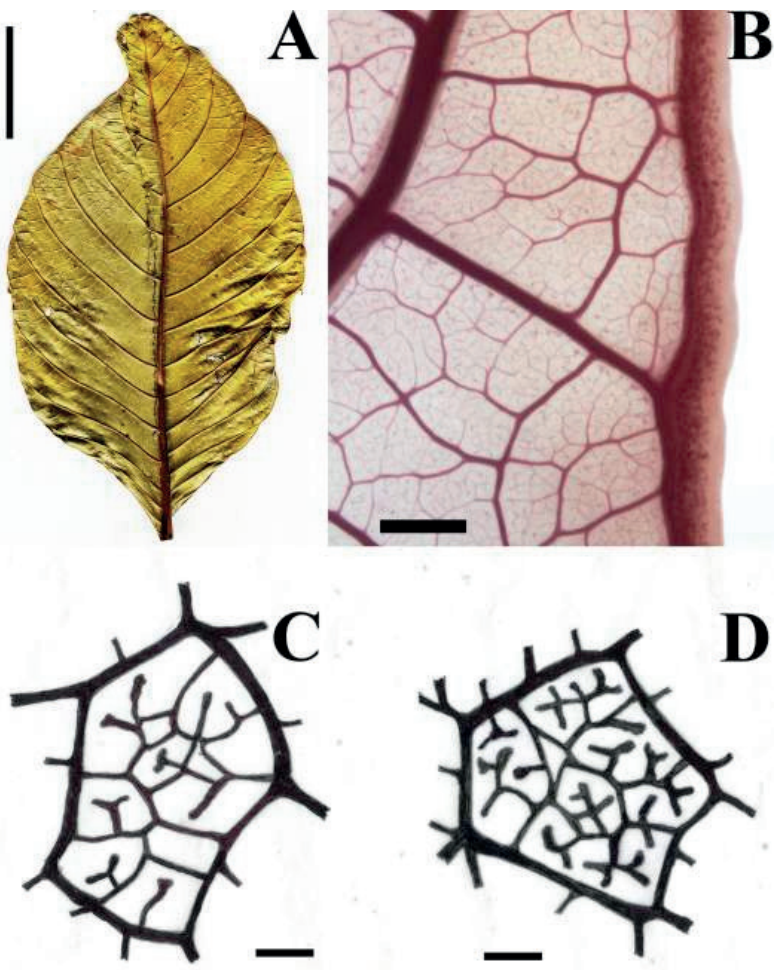

FIGURA 5 Detalhes da venação foliar de P. rigida. $5 \mathrm{~A}$ : folha prensada e escaneada: padrão; 5 B: detalhe das nervuras terminais do bordo; $5 \mathrm{C}$ : aréolas e nervúrulas em folhas de cerrado; 5 D: aréolas e nervúrulas em folhas de campo rupestre. Barras $=5,0 \mathrm{~cm} \mathrm{A;} 1000$ $\mu \mathrm{m} \mathrm{B} ; 200 \mu \mathrm{m}$ C e D.

FIGURE 5 Leaf venation details of $P$. rigida. A: scanned leaf; B: veins from leaf margin; $C$ : areoles and minor veins in leaves from cerrado plants; $D$ : areoles and minor veins in leaves from campo rupestre plants. Bars $=5 \mathrm{~cm} \mathrm{~A}$; $1000 \mu \mathrm{m} \mathrm{B} ; 200 \mu \mathrm{m} \mathrm{C}$ and D.

Observa-se uma área foliar 129,97\% maior nas plantas de cerrado em comparação com o campo rupestre (Tabela I). Resultado semelhante foi observado para o comprimento das folhas, que foi $42,67 \%$ maior nas plantas de cerrado, enquanto que a largura foliar apresentase $40,14 \%$ maior nessas plantas em comparação com aquelas do campo rupestre (Tabelal).

Os diferentes ambientes também modificaram as características anatômicas das folhas de $P$. rigida. Observou-se uma densidade estomática $21,42 \%$ maior nas plantas de cerrado enquanto os estômatos das plantas amostradas nesse ambiente apresentaram estômatos com diâmetros polares e equatoriais respectivamente $20,22 \%$ e $37,75 \%$ maiores em relação às plantas de campo rupestre (Tabela I).

A espessura da epiderme da face adaxial foi $66,09 \%$ maior nas plantas de cerrado enquanto que, na face abaxial, esse tecido apresentou médias $27,26 \%$ maiores nas plantas de cerrado em comparação com 
TABELA I Modificações na estrutura foliar de Palicourea rigida em ambiente de cerrado e campo rupestre. As médias seguidas de mesma letra nas linhas não diferem entre si pelo teste de Scott-Knott para $p<0,01$. Entre parênteses está indicado o desvio padrão.

TABLE I Leaf structure modifications of Palicourea rigida plants from cerrado and campo rupestre environments. Means followed by the same letter in lines don't differ significantly at Scott-Knott test to $p<0.05$.

\begin{tabular}{|c|c|c|}
\hline Características & Cerrado & Campo rupestre \\
\hline Área foliar $\left(\mathrm{cm}^{2}\right)$ & $163,144( \pm 6,24) \mathrm{a}$ & $71,068( \pm 11,88) b$ \\
\hline Comprimento foliar (cm) & $20,764( \pm 1,37) a$ & $14,554( \pm 1,44) b$ \\
\hline Largura foliar (cm) & $|2,24|( \pm 0,88) a$ & $8,735( \pm 0,95) b$ \\
\hline $\begin{array}{l}\text { Densidade estomática } \\
\text { (estômatos mm²) }\end{array}$ & $340( \pm 29,32) a$ & $280( \pm 37,89) b$ \\
\hline $\begin{array}{l}\text { Diâmetro polar estomático } \\
\qquad(\mu \mathrm{m})\end{array}$ & $35,296( \pm 2,22) a$ & $29,360( \pm 1,99) b$ \\
\hline $\begin{array}{c}\text { Diâmetro equatorial } \\
\text { estomático }(\mu \mathrm{m})\end{array}$ & $24,757( \pm 1,73) a$ & $17,972( \pm 1,23) b$ \\
\hline $\begin{array}{l}\text { Espessura da epiderme } \\
\text { adaxial }(\mu \mathrm{m})\end{array}$ & $69,072( \pm 2,27) a$ & $41,588( \pm 2,69) b$ \\
\hline $\begin{array}{c}\text { Espessura da epiderme } \\
\text { abaxial }(\mu \mathrm{m})\end{array}$ & $38,262( \pm 1,47) a$ & $30,066( \pm 1,92) b$ \\
\hline $\begin{array}{l}\text { Espessura do parênquima } \\
\text { paliçádico }(\mu \mathrm{m})\end{array}$ & $73,547( \pm 6,08) \mathrm{a}$ & $56,770( \pm 3,40) b$ \\
\hline $\begin{array}{l}\text { Espessura do parênquima } \\
\text { esponjoso }(\mu \mathrm{m})\end{array}$ & $167,572( \pm 7,78) a$ & $|4|, 345( \pm 5, \mid 7) b$ \\
\hline
\end{tabular}

- campo rupestre (Tabela I). O parênquima paliçádico também apresentou médias $29,55 \%$ maiores nas plantas de cerrado enquanto que 0 parênquima esponjoso demonstrou valores $18,55 \%$ superiores nas plantas coletadas nesse ambiente em comparação ao campo rupestre (Tabela I).

O ambiente de campo rupestre é tipicamente caracterizado por vegetação rasteira e ambientes abertos (ALVES et al., 20l4) enquanto o cerrado sensu stricto pode conter vegetação arbórea abundante representada por diversas famílias botânicas (NETTESHEIM et al., 2010). O ambiente de campo rupestre possui solos particularmente pobres e um período seco bastante característico (ALVES et al., 2014). Portanto, os ambientes de campo rupestre exibem uma maior área aberta e sujeita a maior radiação incidente com solos bastante pobres e sujeitos à restrição hídrica, ocorrendo maior quantidade de fatores desfavoráveis quando comparado ao cerrado. Sabe-se que folhas desenvolvidas em ambientes com maior radiação apresentam menor área em comparação a folhas mais sombreadas (KUBINOVÁ, 1991). E espécies arbóreas podem exibir variação na anatomia foliar com folhas mais espessas, com menor área e maior densidade estomática em função de posições mais altas na copa, que recebem maior radiação e sofrem restrição hídrica (PIRES et al., 20I5). Portanto, as maiores médias observadas para as características foliares nas plantas de $P$. rigida em ambiente de cerrado podem ser atribuídas a características ambientais menos inóspitas que levaram a formação de folhas maiores e mais funcionais em comparação com o campo rupestre. De fato, folhas de sol (mais espessas e com maior densidade estomática) podem ser associadas a maiores teores de clorofila e fotossíntese (DIAS et al., 2007). Além de características mais funcionais como maior espessura do mesofilo e maior densidade estomática, a maior área foliar de $P$. rigida em ambiente de cerrado pode levar a uma maior fotossíntese que pode possibilitar um maior crescimento e porte das plantas em ambiente de cerrado comparado ao campo rupestre.

\section{CONCLUSÕES}

As características observadas nas folhas de Palicourea rigida, tais como: epiderme unisseriada, parênquima paliçádico uniestratificado, diversos tipos de cristais de oxalato de cálcio, também referidos por Lersten (1974), feixes vasculares colaterais, a distribuição dos tecidos de sustentação (colênquima e esclerênquima), mostram que a organização reflete as características da família Rubiaceae, citadas por Metcalfe e Chalk (1950).

As maiores médias observadas para as características foliares nas plantas de $P$. rigida em ambiente de cerrado podem ser atribuídas a características ambientais menos inóspitas que levaram a formação de folhas maiores e mais funcionais em comparação com o campo rupestre. Além das características mais funcionais como maior espessura do mesofilo e maior densidade estomática, a maior área foliar de $P$. rigida em ambiente de cerrado pode levar a uma maior fotossíntese que pode possibilitar um maior crescimento e porte das plantas em ambiente de cerrado comparado ao campo rupestre.

\section{REFERÊNCIAS}

ALVES, R. J. V.; SILVA, N. G.; OLIVEIRA, J. A.; MEDEIROS, D. Circumscribing campo rupestre: megadiverse Brazilian rocky montane savanas. Brazilian Journal of Biology, $v$. 74, n. 2, p. 355-362, 2014.

BARROSO, G. M.; PEIXOTO, A. L.; ICHASO, C. L. F. ; COSTA, C. G.; GUIMARES, E. F.; LIMAS, H. C. de. Sistemática de angiospermas do Brasil. Viçosa, MG: UFV, 1986. v. 2, $377 \mathrm{p}$.

BEIGUELMAN, B. Considerações sobre a morfologia dos estomas de Annona coriacea Mart., Byrsonima coccolobifolia Kunth., Erythroxylum suberosum St. Hil. e Ouratea Spectabilis (Mart.) Eng. Revista Brasileira de Biologia, Rio de Janeiro, v. 22, n. 2, p. I14-124, 1962. 
CAMPOS, M. T. V. A.; ZAPPI, D. C.; CALIÓ, M. F.; PIRANI, J. R. Flora de grão mogol, Minas Gerais: Rubiaceae. Boletim de Botânica da Universidade de São Paulo, São Paulo, v. 24 , p. 4 I-67, 2006.

DIAS, J.; PIMENTA, J. A.; MEDRI, M. E.; BOEGER, M. R. T.; FREITAS, C. T. Physiological aspects of sun and shade leaves of Lithraea molleoides (Vell.) Engl. (Anacardiaceae). Brazilian Archives of Biology and Technology, Curitiba, v. 50, n. I, p. 91-99, Jan. 2007.

FELLIPE, G. M.; ALENCASTRO, F. M. M. R. de. Contribuição ao estudo da nervação foliar das compostas dos cerrados: I., Tribus: Helenieae, Heliantheae, Inuleae, Mutiseae, e Senecioneae. Anais da Academia Brasileira de Ciências, Rio de Janeiro, v. 38, p. I25-I57, 1966.

FERREIRA, D. F. Sisvar: a computer statistical analyze sistem. Ciência e Agrotecnologia, Lavras, v. 35, n. 6, p. 1039 I042, nov./dez. 201 I.

FOSTER, A. S. Practical plant anatomy. New York: Van Nostrand, 1949. 228 p.

FREITAS, L. J. M.; BARATTO, D. M.; PEREIRA, P. S.; CONTINI, S. H. T.; MOMM, H. G.; BERTONI, B. W.; FRANÇA, S. C.; PEREIRA, A. M. S. Loganin production in Palicourea rigida (Rubiaceae) from populations native to Brasilian Cerrado. Journal of Medicinal Plantas Research, v. 5, n. 12, p. 2559-2565, 2011 .

GOMES, D. M. S.; MANTOVANI, A.; VIEIRA, R. C. Anatomia foliar de Psychotria tenuinervis Mull. Arg. e P. stenocalyx Mull Arg. (Rubiaceae). Arquivos de Biologia e Tecnologia, São Paulo, v. 38, n. I, p. I5-33, 1995.

JENSEN, W. A. Botanical histochemistry: principles and practice. San Francisco: W. H. Freeman, 1962. 408 p.

HICKEY, L. J. Classification of the architecture of dicotyledons leaves. American Journal of Botany, Ohio, v. 60, n. I, p. 17-33, 1973.

KRAUS, J. E.; ARDUIN, M. Manual básico de métodos em morfologia vegetal. Seropédica: EDRU, 1997. 198 p.

KUBÍNOVÁ, L. Stomata and mesophyll characteristics of barley leaf as affected by light: stereological analysis. Journal of Experimental Botany, Oxford, v. 42, n. 8, p. 995-100I, May 1991.

LERSTEN, N. R. Morphology and distribution of colleters and crystals in relation to the taxonomy and bacteria leaf nodule symbiosis of Psychotria (Rubiaceae). American Journal of Botany, Ohio, v. 6I, n. 9, p. 973-98I, 1974.

MABBERLEY, D. J. The plant-book: a portable dictionary of the vascular plants. Cambridge: Cambridge University Press, 1997, $858 \mathrm{p}$.
MENDONÇA, A. C. A. M.; SILVA, M. A. P. da; SEIXAS, E. N. C.; SANTOS, M. A. F. dos. Rubiaceae: aspectos ecológicos e reprodutivos. Caderno de Cultura e Ciência, Cariri, v. I2, n. 2, p. 8-19, 2013.

METCALFE, C. R. Anatomy of the Dicotyledons: I., systematics anatomy of leaf and stem, with a brief history of the subject. Oxford: Clarendon, 1979. 275 p.

METCALFE, C. R.; CHALK, L. Anatomy of the dicotyledons: leaves, stem and wood in relation to taxonomy with notes on economic uses. Oxford: Clarendon, 1950. I500 p.

NETTESHEIM, F. C.; CARVALHO, D. C.; FONSECA, C. C.; NUNES, R. S.; CAVALCANTI, D. M.; GABRIEL, M. M.; MENEZES, L. F. T. Estrutura e florística do estrato arbóreo no cerrado sensu stricto de Buritis, Minas Gerais, Brasil. Rodriguésia, Rio de Janeiro, v. 6I, n. 4, p. 731747, 2010.

OLIVEIRA, A. K. M.; MATIAS, K.; LOPES, S. S.; FONTOURA, F. M. Allelopathy and influence of leaves of Palicourea rigida (Rubiaceae) on seed germination and seedling formation in lettuce. Bioscience Journal, Uberlândia, v. 30, p. 938-947, 20I4. Suplemento 2.

PEREIRA, Z. V.; MEIRA, R. M. S. A.; AZEVEDO, A. A. Morofoanatomia foliar de Palicourea longepedunculata Gardiner (Rubiaceae). Revista Árvore, Viçosa, v. 27, n. 6, p. 759-767, 2003.

PIRES, M. F.; PEREIRA, M. P.; CASTRO, E. M.; BARBOSA, S.; PEREIRA, F. J. Micromorfometria foliar de Schinus molle L. (Anarcadiaceae) em diferentes alturas na copa. Cerne, Lavras, v. 2I, n. I, p. 17-25, mar. 2015.

ROBBRECHT, E. Tropical wood Rubiaceae. Opera Botanica Belgium, v. I, p. I-27I, 1988.

SILVA, M. S.; PEREIRA, A. M. S.; MOREL, L. J.; FRANÇA, S. C.; BERTONI, B. W. Association of loganin contents with the genetic characterization of natural populations of Palicoura rigida Kunth determined by AFLP molecular markers. Biochemical Systematics and Ecology, v. 5I, p. 189194, 2013.

VIEIRA, R. C. Tocoyena bullata (Vell.) Mart. (Rubiaceae): anatomia foliar. Rodriguesia, Rio de Janeiro, v. 66, n. 40, p. 33-39, 1988.

VIEIRA, R. C.; GOMES, D. M.; FERRAZ, C. L. A. Anatomia foliar de Psychotria nuda Wavra e Psychotria leiocarpa Mart. Rubiaceae. Hoehnea, São Paulo, v. 19, n. I/2, p. 185-195, 1992.

ZAPPI, D. C.; CALIÓ, M. F; PIRANI, J. R. Flora da Serra do Cipó, Minas Gerais: Rubiaceae. Boletim de Botânica da Universidade de São Paulo, São Paulo, v. 32, n. I, p. 7I140, 2014. 